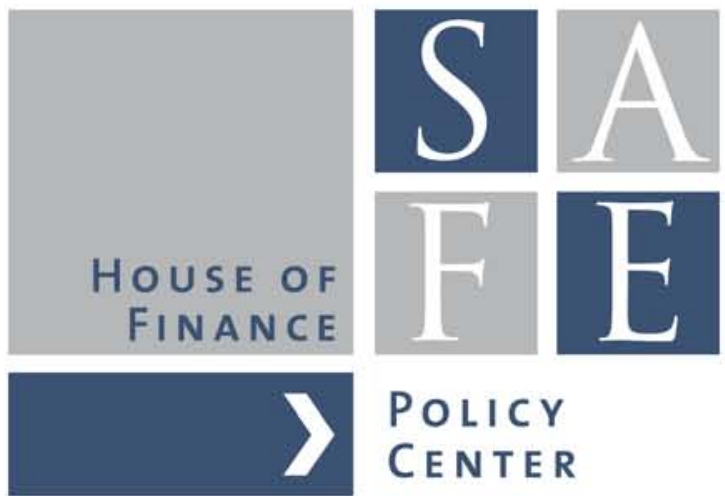

Otmar Issing

\title{
Forward Guidance: A New Challenge for Central Banks
}

White Paper Series No. 16

SAFE I Sustainable Architecture for Finance in Europe A cooperation of the Center for Financial Studies and Goethe University Frankfurt 
SAFE Policy papers represent the author's personal opinions and do not necessarily reflect the views of the Research Center SAFE or its staff. 


\title{
Forward Guidance: ${ }^{1}$ A New Challenge for Central Banks
}

\author{
Contribution to the Athens Symposium \\ "Banking Union, Monetary Policy and Economic Growth" \\ Athens, 19 June 2014
}

\section{Otmar Issing ${ }^{2}$}

Forward guidance is the most recent stage of communication in a long and ongoing process of central banks making their decisions and the underlying process increasingly transparent. Yellen (2012) even sees forward guidance as a revolution, marking a large leap forward in the previously steady evolution of central bank communication.

In the past, central banking was surrounded by what Brunner (1981) called "a peculiar and protective political mystique." Central banking was, in his view, presented as an esoteric art to which only the initiated elite had access. And as it is impossible to articulate an esoteric art in explicit and intelligible words and sentences, "communication with the uninitiated breaks down."

A striking case can be found in the 1928 testimony by the Deputy Governor of the Bank of England Sir Ernest Harvey, when he defended the bank's position before the Macmillan Committee (see Issing 2005):

Harvey: "I confess I am sometimes nervous at the thought of publication unless it is historical. The question is whether, when it is merely historical it is of any particular value, or whether from the fact that it is issued from the central bank undue importance may be attributed to certain things that are stated, more importance than perhaps they merit..." Committee member Keynes: "Arising from Professor Gregory's questions, is it a practice of the Bank of England never to explain what its policy is?"

Harvey: "Well, I think it has been our practice to leave our actions to explain our policy."

\footnotetext{
${ }^{1}$ I am grateful for valuable comments by A.Orphanides and W.White.

${ }^{2}$ President, Center for Financial Studies
} 
Keynes: "Or the reasons for its policy?"

Harvey: "It is a dangerous thing to start to give reasons."

Keynes: "Or to defend it against criticism?"

Harvey: "As regards criticism, I am afraid though the Committee may not all agree, we do not admit there is need for defence; to defend ourselves is somewhat akin to a lady starting to defend her virtue."

Although this sounds as if it came from medieval times, the governor's remarks are not as foolish as they may initially seem. The debate on the extent to which public information can crowd out sometimes better private information has not been resolved yet. And to say that "it has been our practice to leave our actions to explain our policy" touches upon a key problem of central bank communication. If a monetary decision were the mechanical outcome of a strictly rule-based strategy containing no discretionary element, and if the public were sufficiently well informed about the rule and could rely on strict adherence of the central bank, the communication problem would be solved satisfactorily by just publishing the decision. However, this is certainly not what Governor Harvey had in mind, nor what any central bank has ever claimed.

\section{The role of communication}

Communication of the central bank has two goals to fulfill. One is the obligation to be accountable to the public for its policy. In this sense, accountability is the counterpart of independence. The other is to make monetary policy as effective as possible. Monetary policy can only fix the central bank interest rate, and thereby control the very short end of the interest rate spectrum. The influence of the central bank on the long end depends on market expectations regarding future central bank decisions (and their impact on inflation etc.). Woodford (2005) goes so far as to say that very little else, other than expectations about policy, matters.

Only reluctantly did central banks react to the challenge of being transparent and using communication as a tool to guide expectations. Up until the nineties, the Fed, for example, did not even publish decisions taken by the FOMC. The Bundesbank's main message was, "Trust us, we will defend the stability of the Deutsche Mark under all circumstances." 
Considering the high degree of credibility it had gained, one could argue in retrospect that this was a simple and clear form of forward guidance. The effectiveness of this approach stood the test of the turbulent phase after German reunification, when there was considerable pressure on the Bundesbank to be-under these special circumstancestemporarily less "dogmatic" about the goal of price stability. As the development of longterm interest rates demonstrates, the markets were convinced that the Bundesbank would bring back the inflation rate from levels of more than $4 \%$ to its (implicit) "normative" rate of 2\% (see Issing 2005).

In the nineties, central banks worldwide increasingly extended their communication. Since then, transparency has become a mantra and has triggered a kind of competition between central banks for the position of being "the champion." This reflected pressure by the media, markets, and academics. As a result, central banks internalized new strands of research.

One can distinguish two dimensions of steering market expectations. First, it includes shortterm indications about policy inclinations in the run-up to policy decisions. Financial markets do not like to be surprised by such decisions. Central banks, reacting to those concerns, are confronted with the difficulty of making their communication on the expected decision conditional on the development of the situation.

The second dimension relates to the medium and longer term. The challenge here is to ensure consistency between the sequence of individual decisions and the mandate of the central bank. If this consistency is achieved, monetary policy is predictable in the short run and credible in the long run.

Over time, central banks have used all forms of communication to provide transparency in order to allow for accountability and contribute to the effectiveness of monetary policy. These range from published minutes or statements, to press conferences, publications like monthly bulletins, and speeches by governors and other members of the decision-making body. Guaranteeing consistency between all these means of communication is obviously a tremendous challenge. 


\section{Forward Guidance}

A few central banks, namely the Reserve Bank of New Zealand, Norges Bank and Sveriges Riksbank, went beyond the common practice and started to publish projections of the future path of the policy rate. The financial crisis and the zero bound were seen as a new challenge for central banks using communication to guide market expectations (Bernanke 2013). Yellen (2012) diagnosed a revolution in thinking about central bank transparency, which has come to be known as forward guidance. Its key element is the announcement that the central bank expects a highly accommodative stance of monetary policy to remain appropriate for a considerable time after the recovery strengthens. Because the central bank rate is at (or close to) the zero bound, forward guidance tries to create an additional easing effect by signalling that the rate will be kept low for a longer period than the public actually expects. This effect would be achieved by encouraging investors to shift their portfolio into longer maturities, thereby reducing long-term rates. In addition, forward guidance is expected to reduce volatility in the markets.

So far, different forms of forward guidance have been adopted by different central banks (ECB 2014).

1. Pure qualitative forward guidance. This approach includes neither an explicit end-date, nor a numerical threshold, nor any explicit reference to the conditions which are relevant for a change in policy. A typical example is the announcement of the Fed in 2003 that "policy accommodation can be maintained for a considerable period."

2. Qualitative forward guidance conditional on a "narrative" about the macroeconomic conditions under which the present policy will prevail. This is the approach preferred by the ECB.

3. Calendar-based forward guidance. This form was applied by the Fed when, on 9 August 2011, the terms for keeping the federal funds rate at low levels "for some time" and "an extended period of time" was replaced by "at least through mid-2013." 
4. Outcome-based forward guidance explicitly sets numerical conditions for a future change in policy. Again, the Fed can be taken as an example for defining an endpoint for the continuation of the present policy: "...at least as long as the unemployment rate remains above $6 \frac{1}{2}$ percent, inflation between one and two years ahead is projected to be no more than a half point above the Committee's 2 percent longer run goal, and longer-term inflation expectations continue to be well anchored" (December 2011). The Bank of England adopted outcome-based guidance in August 2013, conditional exclusively on a numerical threshold for unemployment, before announcing an update in February 2014 that it would take into account a broader range of indicators.

\section{Some critical remarks}

There exists broad agreement that the financial crisis ended in an economic downturn which is different from previous ones, because it is deeper than just a "normal" recession. Central banks have reacted by extending interest rate cuts to the extreme (zero) and adopting unorthodox measures. Forward guidance is intended to make the accommodative monetary policy under these circumstances as effective as possible. But, can this new communication tool achieve this goal?

The great recession creates a huge challenge for central banks. Markets and agents are confronted with heightened uncertainty. Forward guidance is supposed to reduce the uncertainty. But how convincing is this as the central bank, too, is sailing through uncharted waters? All forms of forward guidance practiced so far boil down to a kind of promise that the central bank will raise the policy rate (and reduce or stop quantitative easing) later than the public expects. In concrete terms this means that the central bank for some time will tolerate a higher rate of inflation than its implicit or announced goal.

The aforementioned intention of this communication - to induce investors to shift their portfolio into long-term assets, thereby reducing long-term interest rates - is expected to have an expansionary effect on the economy. The extent to which the interest rate will actually be lowered, or economic activity react to the policy, however, depends on various factors. 
Announcing a date or a numerical outcome for the continuation or ending of the present accommodation depends on a model from which the central bank draws this conclusion. Two considerations have to be regarded here. One is of a general nature, namely, that uncertainty about the result of forecasts increases with the length of the time horizon. How can a communication reduce uncertainty when its ambition is to extend the horizon to a longer than usual period? And how is the model constructed? In practically all models currently in use, the output gap (or other comparable measures of slack) plays a major role. However, Orphanides and others have demonstrated time and again that real-time data for the output gap are among the shakiest and most unreliable data. Since 1999, almost half the time, the sign (!) of the real-time estimates of the IMF on the output gap turned out to be wrong. Is it not astonishing that, notwithstanding this endemic problem (Orphanides 2013), communication intended to reduce uncertainty is based on information which, with great likelihood, will turn out to be wrong (and biased to the downside)?

A fundamental problem is uncertainty about the equilibrium real interest rate. Without reliable information on its value, it is impossible to calculate a path for the nominal interest rate for some time ahead. As a consequence, communicating a medium- or even long-term interest rate path is dangerous. Whereas the bulk of the literature is based on the seminal work of K. Wicksell, it is often forgotten (or was never realized) that Wicksell himself recognized this uncertainty, and did not suggest formulating monetary policy by starting from the real rate. ${ }^{3}$

A related problem is binding the path of monetary policy explicitly (output-based forward guidance) or implicitly (qualitative) to an unemployment rate which is seen as a target of monetary policy. As practice has shown, data on unemployment-which are lagging indicators and exposed to short-term volatility-might be influenced, for example, by the labour force participation rate. A fall in the unemployment rate might therefore be anything but a signal that monetary policy "succeeded" in reducing unemployment. The need to adjust the figure for this or other reasons can be seen as ex post evidence that such an approach does not reduce uncertainty, but will rather create confusion. And, more

\footnotetext{
${ }^{3}$ I am grateful to A. Orphanides for reminding me of this important aspect.
} 
fundamentally, M. Friedman's (1962) argument that monetary policy should not target real variables is still valid.

Basing forward guidance on the achievement of a specific goal for employment or unemployment is therefore problematic in several aspects. This is even more the case when such an announcement is connected with the message that the central bank will, for some time, tolerate an inflation rate higher than its long-term goal. Such an approach must be based on the assumption that inflationary expectations remain firmly anchored on the credibility of the central bank to steer inflation back to target.

An extended phase of low inflation is a valid argument that that might be the case, but is no guarantee. Expectations could just reflect current developments. When a central bank signals that it will tolerate-or even try to "produce" - higher inflation to foster employment (or growth), it obviously believes in a trade-off between inflation and unemployment. As a consequence, such a central bank implicitly signals that it might extend the period of higher inflation, or accept an even higher inflation rate, to promote employment in case the targeted level of unemployment is not yet achieved. If the central bank makes the trade-off quasi-official, there would be strong political pressure to apply an accommodative monetary policy to ensure the achievement of higher employment whatever the consequences for inflation might be.

Here lies a fundamental problem of forward guidance: It suffers from the same sort of time inconsistency malaise that it seeks to remedy. Announcing that the policy rate will remain low well into the future does not imply that the central bank, from the perspective of a future date and in the face of rising inflation, will have an incentive to follow through on its commitment. The reason is, of course, that at that future moment, the central bank will be confronted with all the costs associated with keeping its promise, while all the benefits will already have been reaped. Therefore, forward guidance will be very prone to time inconsistency.

It is extremely difficult to forecast the impact of the announced monetary policy (interest rate path) on the economy. New shocks might hit the economy. The time dimension of those 
developments varies with the type and magnitude of shocks, the prevailing financial sentiment, the international environment and many other variables. Is it therefore not impossible to set the horizon for monetary policy and assess its impact in advance (Issing 2002)? A central bank should therefore under no circumstances make any unconditional commitments on its future policy.

Central banks have a tendency to ascribe an importance to market reactions that goes beyond their transmission interest. The reason for this bias lies in the fact that any misperceptions of the central bank's policy by financial market participants can create huge losses. Consequently, praise and complaints from financial agents have become permanent companions of monetary policy. Distinguishing between the perception of conditional and unconditional statements is therefore anything but a simple task.

This problem also arises when it turns out that, for reasons which may be due to confusing signals by the central bank-such as lack of clarity in communication, diverging signals by various members of the decision making body, etc.-agents do not react in the way the central bank intended. Should agents then feel "punished" by decisions of the central bank following its initial intentions, or will the central bank "correct" its policy?

The more forward guidance triggers portfolio shifts into longer maturities, the more difficult the task of deciding on the timing and speed of exit. Rate increases will create losses on fixed income investments. In case the financial sector is not yet seen as robust enough, the central bank might delay the exit (or tapering). In combination with an ambitious goal for employment, the temporary tolerance of higher inflation might become entrenched.

\section{Concluding remarks}

Forward guidance has so far been a process of trial and error. This is demonstrated by the Fed, which has experimented with all forms. But, it is hard to believe that the sequence from qualitative to date-based and finally output-based forward guidance has brought an improvement. 
Insofar as a new and dangerous situation, such as the great recession, is a strong argument for trying new measures, trial and error seems to be the appropriate approach. However, this is not an argument for trying measures which are extremely unlikely to bring progress, while implying substantial risks.

Forward guidance should be seen in the context of a long progression from opaqueness to transparency in central bank decision-making. Can forward guidance be seen as an improvement and does it bring us closer to a kind of optimum? Doubts are already fostered by experience gathered so far. But more importantly, the approach suffers from two implicit fundamental flaws.

\section{Optimal policy?}

First, forward guidance as a more or less pre-announced future interest rate path rests on the idea that monetary policy is a case for optimal control. All the models on which this approach is based are far away from integrating a financial sector accurately enough to adequately reflect the complexity of reality. Errors in monetary policy are, unfortunately, the logical consequence; central banks adopting this approach will end up undermining their credibility. Guidance of expectations based on this approach cannot deliver the expected results; uncertainty (and volatility) finally will not be reduced. By the way, this risk increases with the pretended degree of precision. The difficulty of identifying the proper interest rate path is intensified by the fact that the impact of past monetary policy decisions is stretched over probably varying periods. "Instrument instability" is the consequence (Holbrook 1972).

This problem is aggravated by the fact that there is hardly full consensus (and might never be) on what the optimal policy should be - not in academia, not between central banks, nor within a specific central bank. An interesting case is reported in the minutes of the meeting of the Swedish Central Bank's Executive Board on September 1, 2010. Lars Svensson, then Deputy Governor, believed that the repo rate path in the main scenario of the bank was unreasonably high and "claimed that if the repo rate path in the main scenario is supported by the majority of the board, one must hope that it is still not credible and this will not have very large consequences before it can hopefully be corrected at the next policy meeting." 
There should be competition within the central bank among staff and board members for the best policy (Svensson 2013). "In contentious issues, the side with the best support from theoretical and empirical research and practical experience should be allowed to win. If the dominant view cannot stand up to scrutiny, it does not deserve to be the main view" (p. 18). This is certainly the proper device for research and, in principle, also for finding the best policy in the central bank. But, transparent communication on this process is a daunting challenge. ${ }^{4}$ Even especially good researchers might disagree, opinions and/or the composition of the decision-making body could change, or the unavoidable element of judgment could influence the outcome in a way which is by some seen as "unscientific." And, aside from a few academics, who would fully understand an approach based on complex models? What would be the message to the markets and the general public: trust us because we are basing our decisions on (pretended) infallible research? And, wouldn't the claim for full transparency also include the right-even the obligation!-by those who disagree to warn that even insiders consider the announced future policy risky or even wrong? Is this kind of state-of-the-art forward guidance an instrument to reduce uncertainty and volatility?

\section{Maximal transparency?}

Second, there is another fundamental aspect. The process of enhancing transparency can be interpreted as moving to a kind of optimum. However, this "optimum" often seems to be misunderstood as a "maximum." Society demands transparency from public institutions. For an independent central bank, this requirement is even more pressing. Any selection of information, any retention of knowledge could be seen as a violation of the principle of transparency.

From this perspective, absolute transparency seems to be a necessary counterpart of independence. Yet, demand for more information is almost unlimited. The requests from agents in financial markets (and the media) are insatiable. The experience gathered so far with forward guidance has already delivered a number of telling examples. Yet, maximum

\footnotetext{
${ }^{4}$ Svensson (2013), after having left the central bank, claims that the majority indeed published an excessively high policy-rate path, with the consequence of lower inflation and higher unemployment. "As a forecaster of the policy rate, ex post the market was right and the Riksbank was wrong."
} 
transparency is a mirage, it is theoretically a nirvana approach and practically impossible to achieve (see Issing 2005).

Central banks communicate a lot of information, of very different quality. If the information is too noisy, too uncertain, and if the risk is high that the public might be distracted, it might be better to restrict communication (Dale et al. 2011). It is, for example, a huge challenge to publish the forecasts of a central bank and the underlying uncertainty such that it can be properly understood and assessed by the public.

Not maximum, but rather some kind of optimum of transparency should be the final stage to strive for. The development of forward guidance must be seen as a dynamic process which is anything but fully controlled by the central banks. It will be hard, if not impossible, to go back and reduce communication from what has been practiced so far.

\section{Outlook}

The intention of forward guidance is to reduce the uncertainty of the public about future monetary policy. However, forward guidance risks giving the impression that the central bank can overcome the uncertainty to which the central bank itself is exposed. If the signal on future policy decisions is vague, but still called forward guidance, the value of information is meagre and will trigger calls for "more." If the signal is strong, coming close to an unconditional commitment, the central bank is confronted with an unpleasant choice in case of new data or a new assessment of the situation. Either the central bank sticks to the decision on which financial agents have based their investment decisions, or it revises its communication, thereby causing immediate losses for investors. In the first case, the need for the central bank to change course increases over time; in the second case, forward guidance will immediately lose credibility.

Forward guidance was presented as the culmination of the idea of guiding expectations by pure communication. Practice has demonstrated that this is a misguided idea. This conclusion could have been drawn from sound analysis, without the need to test it in practice. What is presented as state of the art monetary policy is but another example of pretence of knowledge-or, in simpler terms, a violation of the principle “Don't try to be too 
clever." Forward guidance tries to give the impression of a kind of rule-based monetary policy. De facto, however, it is an overambitious discretionary approach which, to be successful, would need much more (or rather better) information than is currently available (for a general discussion see Brunner 1995).

There is no easy way to overcome uncertainty, be it in the process of monetary policy decisions, or in communication. Forward guidance is anything but a magic tool. Transparency rests on two pillars. On the one hand, credibility is the foundation on which any attempt to successfully guide expectations must be based. A clear strategy, and an uncompromising commitment to the final goal of price stability, is essential. On the other hand, communication must be clear and honest about the limits of monetary policy in a world of uncertainty. 


\section{References}

Bernanke, Ben S., 2013. "Communication and monetary policy." Herbert Stein Memorial Lecture, Washington, D.C., November 19.

Brunner, Karl, 1981. "The art of central banking." Center for Research in Government Policy and Business, University of Rochester, Working Paper GPB 81-6.

European Central Bank, 2014. "The ECB's forward guidance." Monthly Bulletin, April 2014, pp. 65-73.

Friedman, Milton, 1968. "The role of monetary policy." American Economic Review 58.1: 117.

Holbrook, Robert S., 1972. "Optimal Economic Policy and the Problem of Instrument Instability." American Economic Review 62.1/2: 57-65.

Issing, Otmar, 2005. "Communication, transparency, accountability: monetary policy in the twenty-first century." Federal Reserve Bank of St. Louis Review, March/April 2005, 87.2: 65-83.

Issing, Otmar, 2002. "Monetary policy in a changing economic environment." Rethinking Stabilization Policy, Federal Reserve Bank of Kansas City (ed.), pp. 183-205.

Issing, Otmar, Vitor Gaspar, Oreste Tristani, and David Vestin, 2005. Imperfect Knowledge and Monetary Policy. Cambridge, UK: Cambridge University Press.

Meltzer, Allan H., 1995. "Monetary, Credit and (Other) Transmission Processes: A Monetarist Perspective." Journal of Economic Perspectives 9.4: 49-72.

Orphanides, Athanasios, 2013. "Is monetary policy overburdened?" BIS Working Paper No. 435.

Dale, Spencer, Athanasios Orphanides, and Pär Österholm, 2011. "Imperfect central bank communication: information versus distraction." International Journal of Central Banking 7.2: 3-39.

Svensson, Lars E.O., 2013. "Forward guidance in theory and practice: The Swedish experience." Working Paper, December 2013.

Woodford, Michael, 2003. Interest and Prices: Foundations of a Theory of Monetary Policy. Princeton, NJ: Princeton University Press.

Woodford, Michael, 2005. "Central bank communication and policy effectiveness." The Greenspan Era: Lessons for the Future, Federal Reserve Bank of Kansas City (ed.), pp. 399-474.

Yellen, Janet L., 2012. "Revolution and evolution in central bank communications." Speech at the Haas School of Business, UC Berkeley, Berkeley, CA, November 13. 